\title{
Design of a 3D Interactive Math Learning Environment
}

\author{
Jason Elliott and Amy Bruckman \\ Georgia Institute of Technology
}

\begin{abstract}
Can 3D graphics help high-school students learn advanced mathematics? Can we create a sufficiently compelling application such that students would choose to play with advanced math concepts for fun? What usability problems does this technology pose for novice users? AquaMOOSE 3D is a desktop 3D environment designed to help students learn about the behavior of parametric equations. AquaMOOSE is based on an educational philosophy called constructionism, which advocates learning through design and construction activities [14]. Students use mathematics to design interesting graphical forms and also create mathematical challenges to share with others. In this paper, we present our iterative design process and the results from a formative evaluation with 105 highschool students in a six-week honors summer math program. We analyse their experiences through log-file analysis, a questionnaire, and interviews. A more detailed case study of one student's positive experiences shows the potential of the system. We conclude that students find the aesthetic qualities of the environment motivating, but usability still poses problems. Opportunities and challenges in leveraging 3D graphics for math learning are discussed. Trade-offs are presented between designing for learner's immediate needs versus leveraging technology to create fundamentally new learning opportunities.
\end{abstract}

\section{Keywords}

Education applications, 3D, math learning, online communities, CSCL, usability, constructionism

\section{INTRODUCTION}

As of fall 2001, the massively multiplayer (MMP) 3D game "Everquest" claimed over 400,000 members, according to a press release by its parent company [21]. Everquest members play an average of 22.4 hours per week [23]. Everquest is only one of a growing number of multi-player and massively multiplayer 3D games claiming growing amounts of human attention. Without in any way denigrating this legitimate new entertainment medium, we may ask-

Permission to make digital or hard copies of all or part of this work for personal or classroom use is granted without fee provided that copies are not made or distributed for profit or commercial advantage and that copies bear this notice and the full citation on the first page. To copy otherwise, or republish, to post on servers or to redistribute to lists, requires specific permission and/or a fee. as we may of any medium whose goal is solely entertainment-is it possible to divert the attention of some entertainment seekers towards an activity that has educational value? Public television was begun with this idea in mind. In the United States, the Public Broadcasting Corporation is a non-profit television network that develops new programs with the goal of being both entertaining and educational. What is the "public television" of the new interactive 3D world?

The AquaMOOSE 3D project began in 1997 with a similar approach in mind. Could we harness the holding power of multi-user 3D worlds for educational aims? It's easy to see how one could pander to students' love of high production values, turning any learning software into a visual showpiece. However, this would not be appropriate. A better system design would make fundamental use of the third dimension and the power of graphics in order to make ideas visual and to further learning objectives. With this in mind, we chose to explore applications for high-school math. Could we combine the power of 3D graphics to show the behavior of functions in three dimensions with the holding power of $3 \mathrm{D}$ worlds to create a compelling math-learning environment?

Our design process began with a technology — 3D graphical avatar worlds. We next began to explore the basic affordances of that technology and look for ways in which it might support learning. It's worth noting that we did not begin by doing field work with math teachers and math students. These figured later in the design process. This decision has significant implications for the way the project evolved, and in this paper we will explore some of the consequences.

Our approach to the design of educational software is based on a specific educational theory: constructionism. The term "constructionism" was coined by Seymour Papert as an extension of Jean Piaget's constructivism. Papert writes that learning, "happens especially felicitously when the learner is engaged in the construction of something external or at least shareable... a sand castle, a machine, a computer program, a book" [14]. Two general design principles for construction kits and activities guide our iterative design process.

Resnick et al summarize these guidelines:

"• Personal connections. Construction kits and activities should connect to users' interests, passions, and experiences. The point is not simply to make the activities more "motivating" (though that, of course, is important). When activities involve objects and actions that are familiar, users 
can leverage their previous knowledge, connecting new ideas to their pre-existing intuitions.

- Epistemological connections. Construction kits and activities should connect to important domains of knowledge - and, more significantly, encourage new ways of thinking (and even new ways of thinking about thinking). A well-designed construction kit makes certain ideas and ways of thinking particularly salient, so that users are likely to connect with those ideas in a very natural way, in the process of designing and creating [18]."

In AquaMOOSE, students make personal connections through the customisation of their avatars and the appeal of the game-like 3D graphics. Epistemological connections are provided through the software's ability to create visual representations of mathematical constructs. Students can see math in a new way. Imagine a student trying to understand topics like parametric equations and 3D polar coordinates aided only by traditional media like graph paper. These ideas are quite abstract and inaccessible. In the graphical 3D world, they are intuitive.

In this paper, we will first present the AquaMOOSE iterative design process and then results from a six-week study that was conducted with 105 high school students at the Georgia Governor's Honors Program during the summer of 2001. A case study of one student's experiences is presented.

\section{RELATED WORK}

Dede and colleagues at George Mason University and Harvard University have designed "Science Space," an immersive virtual reality (VR) environment for teaching physics concepts. They found that "three-dimensional representations seem to aid learners in understanding phenomena that pervade physical space. Being immersed in a 3D environment is also motivating for learners. Learner motivation is high in VR environments, even when novelty effects wear off." However, they note that making environments of this complexity usable is a challenge [6].

While much attention has been paid to immersive virtual reality environments, less work has been presented about desktop 3D environments. In 1988, Brooks presented some techniques that help alleviate the inherent difficulties of understanding a 3D environment. Brooks also called for more research on interfaces and usability guidelines for 3D environments [1]. Since then, more attention has been given to 3D in general, but there are still many unexplored questions related to desktop 3D applications. One of the areas that has received some attention is navigation of a $3 \mathrm{D}$ environment. For example, Vinson [22] discusses the benefit of landmarks to 3D navigation. Tan [19] presents various findings about navigation input schemes for 3D applications.

One of the fundamental goals of our research is to attempt to synergistically combine mathematics and art. The mutually reinforcing potential of math and art has been demonstrated in the past by work on the Logo programming language [13] and the Hypergami project. Hypergami is a CAD system for origami developed by Mike Eisenberg and Ann Nishioka Eisenberg. In Hypergami, students create polyhedral structures that can be printed out and folded on paper to create 3D objects [8].

\section{ITERATIVE DESIGN}

One goal of many educational software projects is to improve students' performance on current curriculum materials and standardized test areas. In the US, teachers and students use that kind of software in preparation for tests such as the SAT and AP exams. Had we begun our work doing interviews with teachers and students, we would no doubt have learned a great deal about their needs in these areas and designed a very different sort of math learning software.

A second approach to designing educational software is to look not to the users' immediate practical needs, but to try to see the bigger picture: to discover ways in which new technologies can fundamentally help create new learning opportunities. Seymour Papert writes:

"In school math, 'analytic geometry' has become synonymous with the representation of curves by equations. As a result every educated person vaguely remembers that $y=x^{\wedge} 2$ is the equation of a parabola. And although most parents have very little idea of why anyone should know this, they become indignant when their children do not. They assume that there must be a profound and objective reason known to those who better understand these things. Ironically, their mathophobia keeps most people from trying to examine those reasons more deeply and thus places them at the mercy of the self-appointed math specialists. Very few people ever suspect that the reason for what is included and what is not included in school math might be as crudely technological as the ease of production of parabolas with pencils! This is what could change most profoundly in a computer-rich world: The range of easily produced mathematical constructs will be vastly expanded." [13]

In the AquaMOOSE project, we chose this second approach. Technology and pedagogy led us to believe there was tremendous potential to facilitate new kinds of math learning. This was our starting point. Feedback from students and teachers was regularly incorporated throughout our iterative design process; however, we began with broader reaching goals than meeting their immediate practical needs. As we will see, this has both strengths (the possibility to create something radically new, thinking outside the box) and weaknesses (the possibility to create something whose benefits are not immediately clear or easily appropriable).

Work on the AquaMOOSE project began in 1997. During the last four years, we have completed three prototypes of our software and conducted several informal and formal user studies. Our first prototype, NetFlyer, was built using the OpenGL language. The second prototype was built with Randy Pausch's Alice software. Our 
current implementation is an MFC application programmed in Visual $\mathrm{C}++$ using a freeware rendering package called Genesis 3D.

\section{NetFlyer}

Our first prototype, called "Net Flyer," was a simple two-person game similar to the American basketball game 'HORSE' (see Figure 1), created in OpenGL. Two players play at one terminal. While one turns his or her back, the first player selects an equation. The second player views the graph of the equation (metaphorically, the path of a flying disk) and tries to guess the original equation. An unsuccessful guess earns a letter in the word "FLYER." The first player to complete the word "FLYER" loses. From this early prototype, we gained insight into the kinds of visualization supports we would need, such as the ability to switch cameras to make use of multiple views of the $3 \mathrm{D}$ world. In informal testing, users noted that the equations were often aesthetically pleasing. They also observed that it was important to keep equations simple if their opponent had any hope of guessing them. The game was more fun in a cooperative mode where you try to provide your partner with an appropriate challenge, rather than a competitive one where you try to stump him or her.

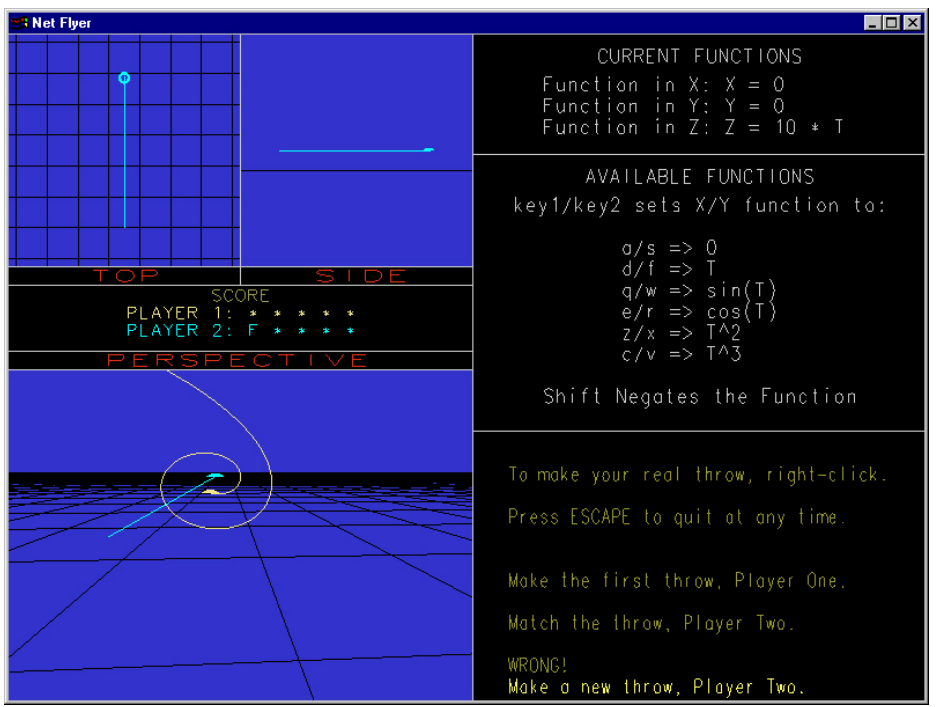

Figure 1: NetFlyer prototype game

\section{Alice Prototype}

The original NetFlyer prototype had a very primitive interface. Since the goals of the project include leveraging the aesthetic appeal of 3D graphics, we knew we needed to improve the look of the software. To move toward that goal, our next prototype was developed using Randy Pausch's "Alice" software [4]. In that version, we created a 3D avatar world with the same flying disk game theme from NetFlyer (see Figure 2).

Compared to our first prototype, this new avatar world seemed much more fun, at least on the surface. The visual look and feel bear a resemblance to game-like environments, and the graphics are attractive. However, it was also much harder to understand the mathematics of motion in 3D. In our first OpenGL prototype, the user's perspective was fixed, making the orientation of the coordinate system consistent and clear. With the moving point of view of a first person system, all the math became harder to understand visually. This observation informed our addition of visualization supports like overlaid axes, grid tools, and multiple viewpoints in our next prototype.

The Alice software proved to be an excellent prototyping tool. However, during our exploration of the Alice prototype, we noted a limitation to our theme: the disk moves in three dimensions, but the user's avatar is stuck in a plane. We also recognized that in order to keep the game-like feel of a 3D world but make mathematical understanding easier again, we needed finer control of the user interface.

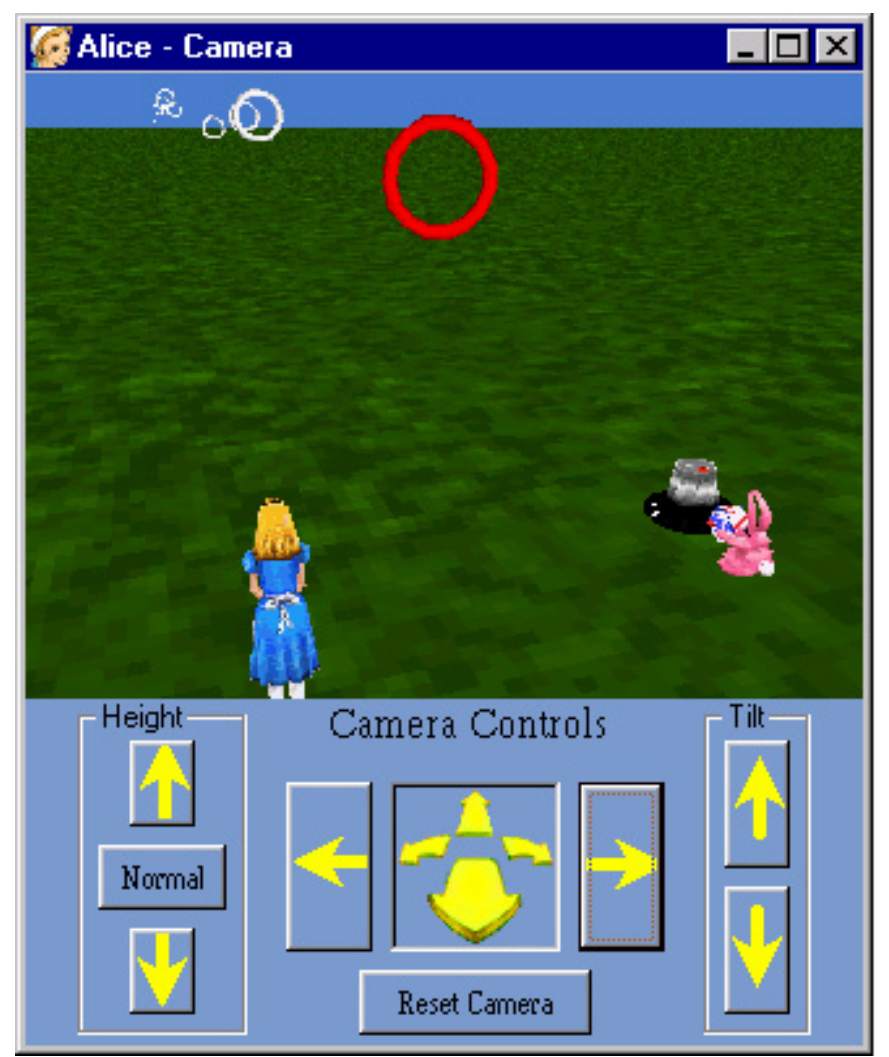

Figure 2: Alice prototype of NetFlyer. Students can throw the disk (knob object) through the rings in a mathematical pattern.

\section{AquaMOOSE 3D}

To better make use of free movement in all three dimensions, we switched to an underwater theme-fish swim freely in three dimensions. Since this work is partly inspired by our prior research on end-user programmable textual worlds in the MOOSE Crossing project $[2,3]$, the new project was jokingly dubbed "AquaMOOSE 3D." While the name was proposed as a joke, it stuck. At this stage, we next moved to a development platform that gives us more control over the user interface: Microsoft Visual $\mathrm{C}++$ and the freeware Genesis 3D rendering engine [9].

Long term, we hope to create a fully programmable, multi-user world. Our goal is for students to be able to create their own video games and share them with others, similar to work with students programming 2D standalone games in Microworlds Logo [11], 
AgentSheets [17], Stagecast [5, 15], and Squeak [10]. On our way to this long-term goal, however, we found more than enough richness and complexity to explore in simply making a single-player 3D mathlearning environment. In our current design, we attempt to create a community of learners by allowing students to create mathematical challenges for one another and share them in a built-in BBS-like interface.

We completed several rounds of formative evaluation prior to and after the study discussed later in this paper. Details about all of the trials we have completed to date are shown in Table 1.

\begin{tabular}{|c|l|}
\hline Date & \multicolumn{1}{|c|}{ Participants } \\
\hline Winter 2000 & Small group of college freshmen \\
\hline Spring 2001 & Advanced math class from Atwood Private School \\
\hline Spring 2001 & Students from Georgia Tech \\
\hline Spring 2001 & Six local high school math teachers \\
\hline Summer 2001 & Georgia Governor's Honors Program \\
\hline Fall 2001 & Math club at Brooks High School (public ${ }^{1}$ ) \\
\hline Fall 2001 & Advanced math class from Atwood Private School \\
\hline
\end{tabular}

Table 1: Dates and participants of AquaMOOSE formative evaluation trials

A small group of college freshman used the AquaMOOSE software in a laboratory session in late 2000 . We observed that co-location was an important aspect of the learning process. Students looked over one another's shoulders sharing excitement about their creations and trading mathematical strategies.

In Spring 2001, we invited a small advanced math class from a local private high school, which we will call Atwood Private School (all student and school names in this paper have been changed to protect their privacy), to evaluate the software in our laboratory. One student in that class, Joel, completed an entire ring course (see The Ring Game below) in about 15 minutes, whereas his classmates and teacher took nearly an hour. On approaching the system, Joel immediately understood exactly what to do, and solved the first segment of the first puzzle in seconds. We were surprised to see such a large range in achievement within an honors class. Based on conversations with Joel and his teacher, we believe his success is attributable to his unusually well developed skill in both mathematics and visualization. Joel was energized by his experience, and continued to explore the system avidly while his classmates finished their work. We are continuing to refine the system's visualization supports to try to make it as immediately accessible to others as it was to Joel.

We then conducted several rounds of formative evaluation with other students at Georgia Tech. The results from these multiple rounds of formative evaluation have helped shape the current system design and user interface.

${ }^{1}$ In the United States, public schools are government funded whereas private schools are paid for by individuals.
In addition to our testing with students, we invited six local math teachers to talk with us about AquaMOOSE and how it might be used in their classes. Based on those conversations, we developed a better idea of how to integrate the application with a pre-calculus curriculum. Some of these ideas are discussed further below (see "School Use").

During the summer of 2001, we conducted our largest formative evaluation with 105 high school math students at the Georgia Governor's Honors Program. This study is discussed below in more detail.

Our next trial was in fall 2001 with an after school math club at a local public high school, which we will call Brooks High School. Brooks High School is in a less affluent suburb of Atlanta. The majority of the students qualify for free or reduced lunch, which is an indicator of socio-economic status. The students at Brooks also enjoyed playing with our software, but were slightly distracted by the informal atmosphere of the math club. This trial was mainly to demonstrate the software to the math teachers at the school in preparation for a future study we will be conducting in some of the pre-calculus classes there.

Also in fall 2001, we conducted a trial with this year's advanced math class from Atwood Private School. The private school students were able to carry on involved conversations with us about the concepts involved in the AquaMOOSE software. It was especially interesting to hear that this particular class had already covered one of the most difficult concepts in our software, 3D polar coordinate space (or spherical polar coordinates).

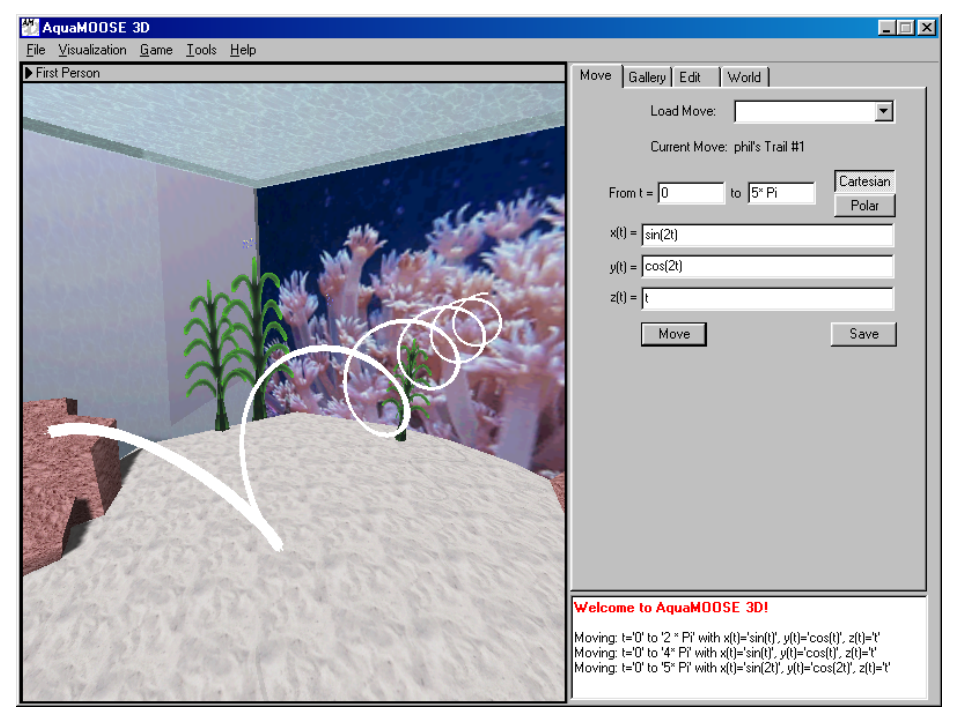

Figure 3: A simple spiral move in AquaMOOSE 3D

As part of our future work, we will conduct two class comparison studies at both Brooks High School and Atwood Private School. In both schools, one teacher has two equivalent pre-calculus classes that we can use for our study. The experimental classes will be using 
lesson plans created specifically for the AquaMOOSE software, while the comparison classes will be using the standard curriculum and materials. These studies will begin in February 2002.

\section{System Design: Swimming Parametrically}

Motion in AquaMOOSE can be specified mathematically, using parametric equations. For example, swimming in a sine wave in $x$ and a cosine in $y$ creates a spiral (see Figure 3 ). Both Cartesian and polar coordinate systems are supported.

A simple template scaffolds the process of entering in mathematical moves (see Figure 4). Each time a mathematical movement is executed, the avatar moves along the programmed function, leaving a trail behind. The trail is an important artifact; it provides the users with a visualization tool for instant feedback, as well as a starting point for conversation.

In many ways, this resembles the Logo programming language [13] in three dimensions. However, there are some important differences. While the math in Logo is done from a first-person perspective to facilitate body-syntonic understanding of math [13], the math in AquaMOOSE is designed to look more like the math students see in school in order to facilitate transfer.

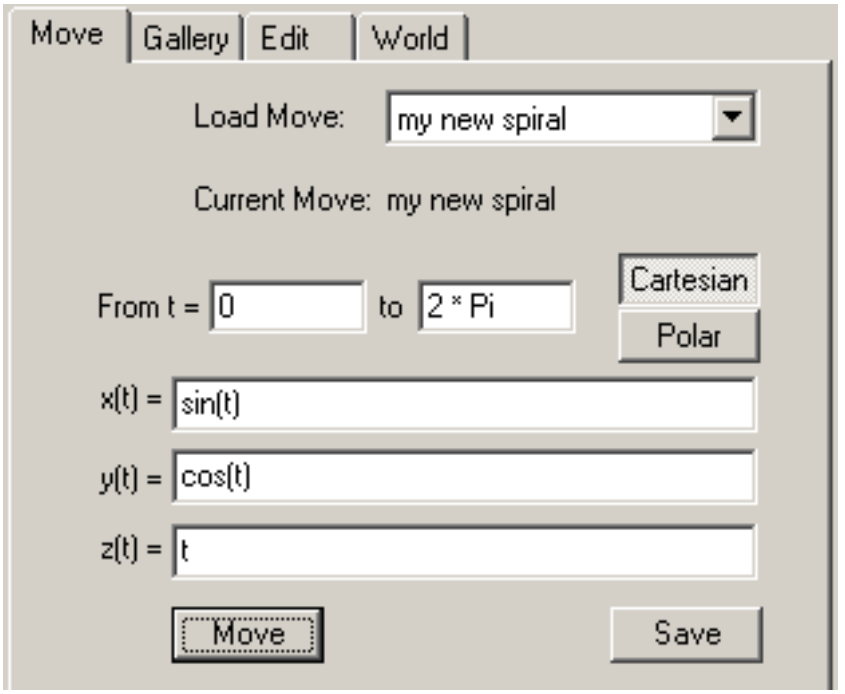

Figure 4: Math move interface

As many HCI researchers have noted, using a $2 \mathrm{D}$ input device (the mouse) to control movement in a 3D space presents usability challenges [12]. In addition to allowing movement specified by mathematical equations, AquaMOOSE also allows free movement directed by the mouse. To choose an interface technique for 3D movement, we surveyed those in use by popular commercial games, and chose the approach taken by Everquest [20] as the most usable based on our informal testing. To enter navigation mode in AquaMOOSE, the user must click and hold the right mouse button. Once in navigation mode, moving the mouse changes the rotation of the avatar (mouse-look) and pressing the left mouse button results in forward motion. The arrow keys may be used at any time to move forwards, backwards, left, or right. Many of our subjects play
Everquest and similar games, and were already familiar with this interface. However, note that while Everquest is a 3D world, gravity largely restricts the user to planar motion. In our underwater environment, completely free motion in all three dimensions makes this interface more challenging to master.

\section{Visualization Supports}

Based on feedback from our earlier prototypes and our formative evaluations of the AquaMOOSE software, we have incorporated several features to help students understand the mathematics they see in the 3D environment (see Figure 5). One tool provides an overlaid representation of the absolute axes in the space, which allows students to quickly connect the parameters of their equations to relative directions in the virtual world. Another set of features provides grid-like visualization tools to help convey the unit size and scale of the environment. Finally, we have provided three customizable windows and four camera angles to allow the students to see both their avatar and the world from multiple perspectives at the same time.

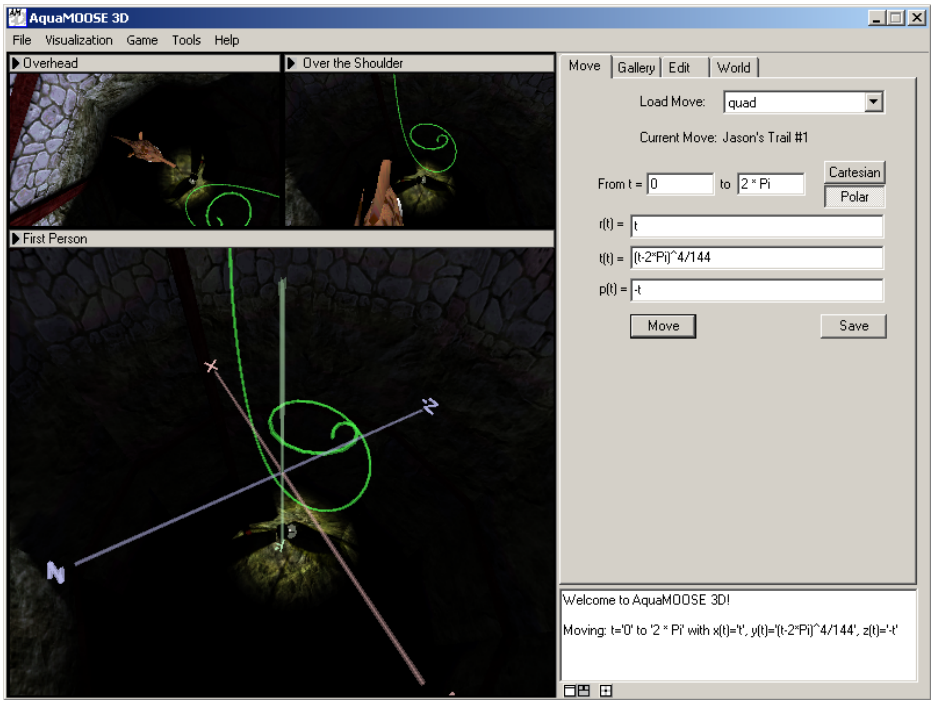

Figure 5: Three window view and axes visualization tool in AquaMOOSE

\section{The Ring Game}

We have provided one prototype game for students to play: a ring game. Students are presented with a set of rings in the water, and are challenged to try to swim through as many as possible with one mathematical function (see Figure 6). This simple game resembles a 3D version of the successful Green Globs software [7]. We hope to make the environment more fully programmable, so that students can create their own games and learn through the process of game design and construction [11].

\section{School Use}

One of the main concerns about using AquaMOOSE in schools is that the math in the software involves concepts that most high school students are not taught. The standard math curricula for most high schools in the United States do not cover topics like 3D math, parametric equations, or spherical polar coordinates. However, 
expanding the educational opportunities for the students is one of the goals of the AquaMOOSE project. We are creating something that teaches a topic radically different from what students are exposed to currently.

We have discovered that this type of radical educational technology is better received in certain types of schools than others. Based on our experiences and conversations with teachers from a variety of schools, it appears that the schools with lower average achievement are often more accepting of radically different teaching tools than we anticipated. The schools with higher average achievement also tend to be flexible about exploring new learning opportunities.

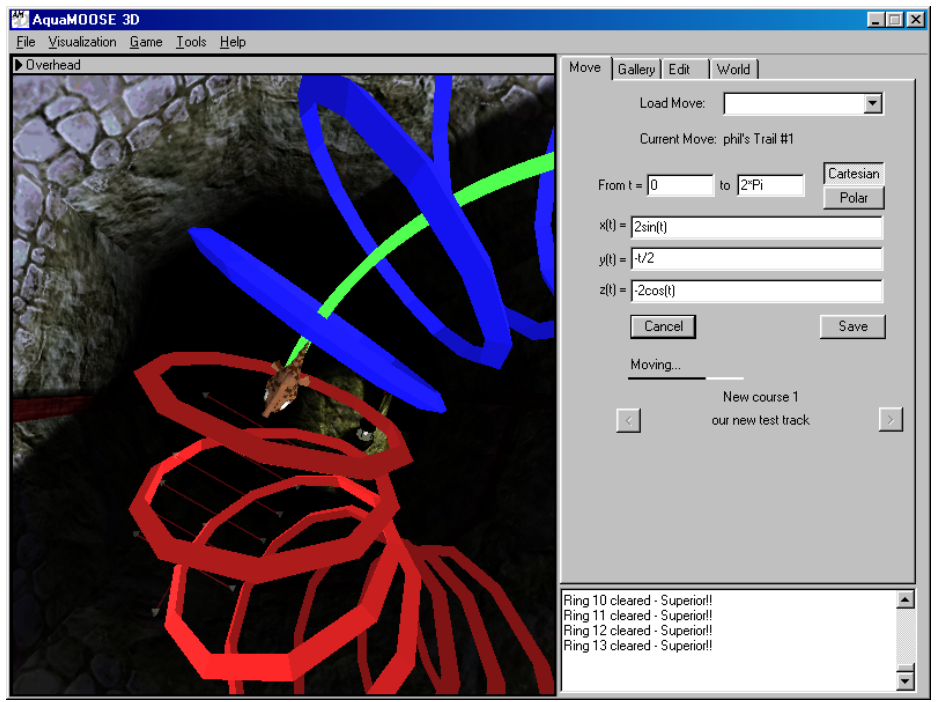

Figure 6: The ring game.

The expectations of the students in lower average achievement schools are very minimal, so the administration does not mind giving the teachers more flexibility in the tools and special programs they use. The students are not expected to do extremely well on standardized tests to begin with, so teaching them material that is not on the test is more acceptable.

In the higher achievement schools, the teachers cover a very large portion of the standard curriculum in a shorter period of time.

Therefore, they tend to also have more time to experiment with new learning tools. The students are often very bright as well, which allows the teachers to introduce new topics quicker and with more success than in other schools.

The schools in the middle of the achievement/expectation scale seem to be the ones where new learning tools are least likely to be accepted. In those schools, the students are struggling to make high scores on standardized tests and do not have the time to devote to extra subject material. While the teachers think new technologies, like the AquaMOOSE software, are compelling and have great potential, they are usually unable to use those new technologies in their classes.

If we had chosen the first approach to educational technology and designed a system based on the immediate practical needs of the teachers and students, our levels of acceptance at these various schools would obviously be different. Since we have chosen to develop a radically new learning opportunity, we have limited our target audience to the students in the lower achievement schools and higher achievement schools.

\section{USER STUDY}

In summer 2001, we conducted a study at the Georgia Governor's Honors Program (GHP) in Valdosta, Georgia. Each year, rising juniors and seniors from Georgia high schools are nominated to attend a six-week summer camp to explore a particular academic area. One of the subject areas offered at GHP is mathematics. There were 105 students majoring in math at GHP that summer. Those students were the subjects for our study. We installed the AquaMOOSE software on 31 computers in the GHP labs that the students used for classes. The students also had access to these labs when classes were not being taught. One of the mandates for the GHP is to enrich students' learning experience beyond what they encounter in the standard curriculum. That aligns very well with our fundamental research goals, making the GHP an ideal setting for this trial.

The study began with a 45-minute demonstration of AquaMOOSE 3D. After that, the students were allowed to log into AquaMOOSE freely. After the introduction, they were not required to use AquaMOOSE at any time. We were more interested in collecting data about how the students used AquaMOOSE during their free time than during required time. There were many other projects and activities at GHP that the students could participate in during their free time. Playing with AquaMOOSE was only one option for the students. All of the data presented in this paper was collected from students who voluntarily used AquaMOOSE throughout the summer.

Students had access to the software in a computer lab setting. Students were able to talk to one another and discuss their progress while using the computers, but generally used the software individually. We collected log files detailing the students' usage of AquaMOOSE over the next six weeks. We returned to GHP half way through the summer and observed the labs during students' free time. Our final visit to GHP was at the end of the program, when we collected anonymous surveys from 103 students ( 2 had left the program during the summer) and conducted interviews with 10 students. The GHP lab administrators and instructors chose the 10 interview subjects who had shown the most interest in AquaMOOSE during the summer. Most of the students who were interviewed found the graphical nature of the program appealing, but wanted more features and more goals to the game. Many of them wanted the fish to be able to jump out of the water or be able to eat other fish. After the study, we did a more in-depth interview with one outstanding student.

\section{Results and Discussion}

There were 105 math majors at GHP who completed parental consent forms for our study. We asked the students to provide their real name and a pseudonym to be used in the software. Many of the students, 
however, did not provide their real name. In addition to the 105 math majors at GHP, students from other programs had access to the computer labs and our software. Since some of the math majors did not provide their correct real name when registering for an online account, they were indistinguishable from the students who had not signed consent forms. Due to that problem, we are only able to report on the data from those accounts that are verifiable as having provided parental consent for our study. Of the 105 math students, 63 created verifiable accounts. Of those 63, 37 students (59\%) performed at least one mathematical movement. The total number of mathematical movements performed by all 63 students was 962 . One student, Mark, was responsible for 340 of those moves. We discuss Mark's experience in greater detail later in this paper.

- Were there things that you wanted to do in the environment that you couldn't do?

- What could we do to improve AquaMOOSE 3D?

- Would you be likely to play with AquaMOOSE 3D if it weren't for a school assignment?

- What were your favorite and least favorite aspects of AquaMOOSE 3D?

Table 2: Sample questions from the survey

\begin{tabular}{|l|l|}
\hline Topic & Sample Comment \\
\hline $\begin{array}{l}\text { Negative } \\
\text { Aesthetics }\end{array}$ & $\begin{array}{l}\text { "[I wanted to] swim in a larger environment } \\
\text { with more space." }\end{array}$ \\
\hline $\begin{array}{l}\text { Positive } \\
\text { Aesthetics }\end{array}$ & $\begin{array}{l}\text { "The environment and the trails were some of } \\
\text { the best parts." }\end{array}$ \\
\hline $\begin{array}{l}\text { Goals to the } \\
\text { game }\end{array}$ & $\begin{array}{l}\text { "I think I might play around with it for a little } \\
\text { bit but not regularly because I don't feel like } \\
\text { there's any goal to it or clear way to win." }\end{array}$ \\
\hline Violence & "[I wanted to] eat the smaller fish." \\
\hline Community & $\begin{array}{l}\text { "I would play... longer if I could interact and } \\
\text { share stuff with my friends." }\end{array}$ \\
\hline Competition & "[I wanted to] race with others." \\
\hline
\end{tabular}

Table 3: Sample comments from surveys

At the end of the six-week study, we distributed anonymous surveys to the students. The majority of the questions on the survey were open-ended discussion questions. See Table 2 for some examples of the questions we asked in the survey. Two reviewers analyzed the surveys. During that analysis, the reviewers noted whether each survey mentioned particular topics of interest. The six topics we chose to explore were negative aesthetics, positive aesthetics, game goals, violence, community, and competition. Some examples of comments for each of the categories are shown in Table 3. Our average inter-rater reliability was $84 \%$.

Out of the 103 students, the number who mentioned aesthetics in a negative manner (56) was almost identical to the number who mentioned positive aspects of the environment (55). Many students requested more structured goals in the environment (18), more violence (14), or more community involvement (12). A few of the students specifically requested that competition be a more integral part of the software (5). These results are shown in Table 4.

\begin{tabular}{|c|c|}
\hline Topic & Occurrences $(\mathrm{N}=103)$ \\
\hline Negative Aesthetics & $56(54 \%)$ \\
\hline Positive Aesthetics & $55(53 \%)$ \\
\hline Goals to the Game & $18(17 \%)$ \\
\hline Violence & $14(14 \%)$ \\
\hline Community & $12(12 \%)$ \\
\hline Competition & $5(5 \%)$ \\
\hline
\end{tabular}

Table 4: Anonymous survey results.

\section{Usability of 3D}

As we expected, the majority of the students mentioned that the 3D graphics in AquaMOOSE were appealing. They enjoyed editing their fish avatars, looking at the math trails they created, and exploring the various 3D worlds that were provided with the software. One of our basic premises for this project is leveraging the appeal of $3 \mathrm{D}$ games to improve students' motivation to learn mathematics.

While they liked the visual look of AquaMOOSE's graphical world, many students experienced problems navigating in it. Some of the problems involved the navigation controls, while others involved representational problems about the virtual world. The size of the environment that we should provide in AquaMOOSE is a difficult design problem. Overall, larger worlds are more popular with the students because they offer more opportunities for exploration. However, there is an important difference between providing interesting places for students to explore and providing large open places for them to explore mathematics. Some of the worlds we included during the GHP study contained interesting "hidden" features that the students could discover through exploration. However, none of the large open spaces we provided were big enough for many of the mathematical moves the students attempted.

One of the most prominent comments we received from the students was that they did not like colliding with walls (referred to as "bonking") because their math moves did not fit in the world. Since the GHP study, we have constructed a few very large worlds to help alleviate some of those space concerns. Simply creating larger worlds does not solve the problem, though. In the larger worlds, moving an avatar from one side of the world to the other with our standard mouse and keyboard navigation controls takes quite some time. The key issue for this problem is the scale factor between the mathematics and the world geometry. We are exploring ways to allow the scale of math functions to be controlled by the students.

Another important aspect that we have learned from this study is that visualization of math trails is interesting to the students. The students had not been exposed to this type of mathematical visualization before, and described wanting more tools to help understand the 
graphical representations. Many students wanted more cameras to move around in the environment. They also wanted more control over what was shown in the cameras that we provided. We are working to implement zooming and panning functions on all cameras in AquaMOOSE 3D.

\section{Mark's Experience}

Of the students at GHP, the most enthusiastic AquaMOOSE user was Mark. His experiences were by no means typical. We chose to examine his success story in detail to learn what went right. We hope to use those insights to guide future iterative design.

Mark is 17 years old, and is a rising senior at a high school in a small Georgia town. Mark's creations in AquaMOOSE drew the attention of his instructors and peers at GHP. His trails consisted of complex equations that he used to represent surface-like structures. Not only were they mathematically sophisticated, but also aesthetically pleasing (see Figures 7-9). We chose to study Mark's experience in detail to explore what factors aided his success. Why did he become more engaged than other students?

To understand Mark's experiences, we have examined logs of his AquaMOOSE usage, interviewed him during GHP, and interviewed him again after GHP. Mark's favorite activities include playing guitar, writing poetry and short stories, and playing around with computer programs. Mark was nominated for GHP in both math and English. GHP offers a program in music as well, but Mark's high school does not nominate students for that major. He decided to attend GHP this past summer partly because he knew it would be good for his academic career, but also because he thought it would be an interesting social experience.

Since Mark attended GHP as a math major, one might guess that his favorite subject in school is mathematics. However, it turns out that is not actually the case. Mark says that his favorite subject changes very often, usually rotating between creative writing, music, and math. "I like all of them a lot, and it just depends on whatever strikes me... what I'm curious about that second," Mark says. Since AquaMOOSE is designed to take advantage of a synergistic combination of math and art, it is not surprising that the most enthusiastic user is equally interested in humanities and mathematics.

Mark thinks he would like to become a computer programmer when he goes on to college next year. However, he feels that his lack of experience with programming during high school will cause him to be behind other students at college. If that proves to be the case, he is considering an engineering career as an alternative. Regardless of which major he chooses, he intends to get a minor in music, which he will use as a back-up career. He entertains thoughts of teaching music at some point during his life.

On arriving at GHP, Mark was surprised by the intelligence of his peers. Entering an environment where the majority of the students around you are the brightest at their respective high schools can be an intimidating experience.

There were many other activities going on at GHP that took away from the students' free time. As Mark pointed out in our interviews, GHP is a social experience as well as an academic one. Many of the students spent a great deal of time playing sports, attending dances, or just hanging out with their new friends. Mark balanced out those activities with his exploration of AquaMOOSE 3D. "There wasn't actually that much stuff that I wanted to go to that I missed," Mark says.
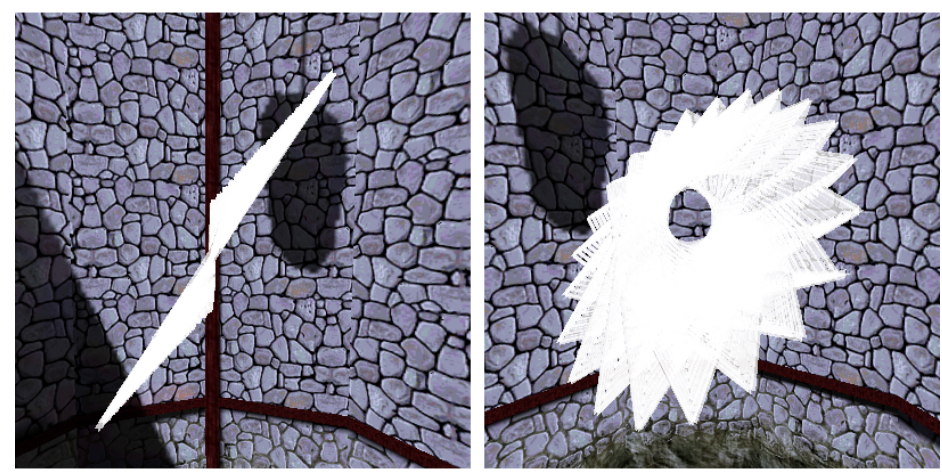

Figure 7: Two views of Mark's "slant vortex"

$$
\begin{gathered}
x(t)=.08 *(t+10) * \cos (40 t) \\
y(t)=.08 *(t+10) * \sin (40 t) \\
z(t)=.08 * t * \sin (40 t)
\end{gathered}
$$

Mark used AquaMOOSE mostly during his free time. After checking his email, he would play around with AquaMOOSE for a while. His typical sessions were anywhere from 15 minutes to an hour. There were other things on the computer that Mark could have used instead of AquaMOOSE, but none of them held his attention for very long. Even a text-based role-playing game that he had seen did not provide him with the entertainment that AquaMOOSE did. Mark usually enjoys playing video games, but is disappointed because many $3 \mathrm{D}$ games in particular contain too much violence and non-intuitive interfaces to the 3D environment. During the six-week period of GHP, Mark used AquaMOOSE for over 10 hours across 16 sessions. Even Mark's friends and teachers at GHP noticed his high level of involvement with the software. The teachers and students alike were impressed with Mark's creations in AquaMOOSE.

Mark's initial reaction to AquaMOOSE was frustration about the equation interface. The template for parametric equations in AquaMOOSE provides an area to enter the $x(t), y(t)$, and $z(t)$ functions. Many of the students, like Mark, entered equations in the form $f(x), f(y)$, and $f(z)$, using $x, y$, and $z$ as the variables instead of $t$. In typical math classes, students most commonly see equations expressed in terms of $x, y$, and $z$. Most students have limited or no exposure to parametric equations expressed in terms of $t$. Since the software evaluated those other variables $(x, y$, and $z)$ to zero, most of Mark's initial attempts at math moves produced no movement at all. The version of AquaMOOSE used at GHP was still in an early prototype stage, and did not provide the appropriate feedback to help 
correct such common mistakes. After a couple of days, though, Mark realized what the equations were expected to look like, and began experimenting with AquaMOOSE again. Mark spent most of his time in AquaMOOSE doing free exploration of complex math equations as opposed to playing with the ring game.

Mark's first exploration of AquaMOOSE involved playing around with the sample spiral move that is included with the software. The spiral consists of the equations:

$x(t)=\sin (t)$

$y(t)=\cos (t)$

$z(t)=t$

These simple equations produce a visually appealing spiral in the 3D environment that was intended to spark the interest of students. After Mark played around with the spiral for a while, he moved on to more complex representations.

This second phase of his exploration resulted in what he describes as "a plane with a spiral coming out of it" (see Figure 7). Another one of Mark's creations produced a trail that looks like a tunnel, except it has "barbed wire" sticking into the tunnel. Mark continued to experiment with various math functions. He added complexity to the equations in various ways. Some of his moves involved combining equations, like $t \sin (t)$ instead of just $\sin (t)$. Some more examples of his work are shown in Figures 8 and 9.

Eventually, a new goal emerged in Mark's mind. He wanted to make a math move that formed a sphere in the 3D environment. He made several attempts at the sphere, but was unable to complete his goal. After the GHP program ended, Mark indicated that he was still thinking about how he could have made the sphere, and was disappointed that he didn't have access to the software any more so that he could test his hypotheses.

In his current high school math classes, Mark does not use computers very often. The main form of technology that he has been exposed to is a graphing calculator. The Texas Instruments graphing calculators are used in many math classes in the United States. Mark feels that AquaMOOSE offers a lot more than the graphing calculator. "Most of the time in math classes you don't have any way to actually represent 3D graphs. Sure, you can do 2D graphs; that's what the TI- 83 is for... AquaMOOSE gave you the chance to do that stuff and had a userfriendly format where you could move around and leave a trail."

Mark speculates that teachers would appreciate using AquaMOOSE in the appropriate classes. He also thought that the teachers would probably spend their own free time exploring AquaMOOSE, since the $3 \mathrm{D}$ visualization is not supported well in other common tools.

A key question remains to be answered: what math did Mark learn? Based on the artifacts he created and our interviews with him, we know that he was successfully able to move from a goal to its execution. He wanted to create trails with particular shapes and aesthetics, and was able to do so through iterative experimentation. We know that he became increasingly fluent with combining basic mathematical elements to achieve his desired goal. We do not know to what extent that mathematical insight will transfer to other contexts. We plan to address the question of transfer in a new study scheduled for 2002 (see below).

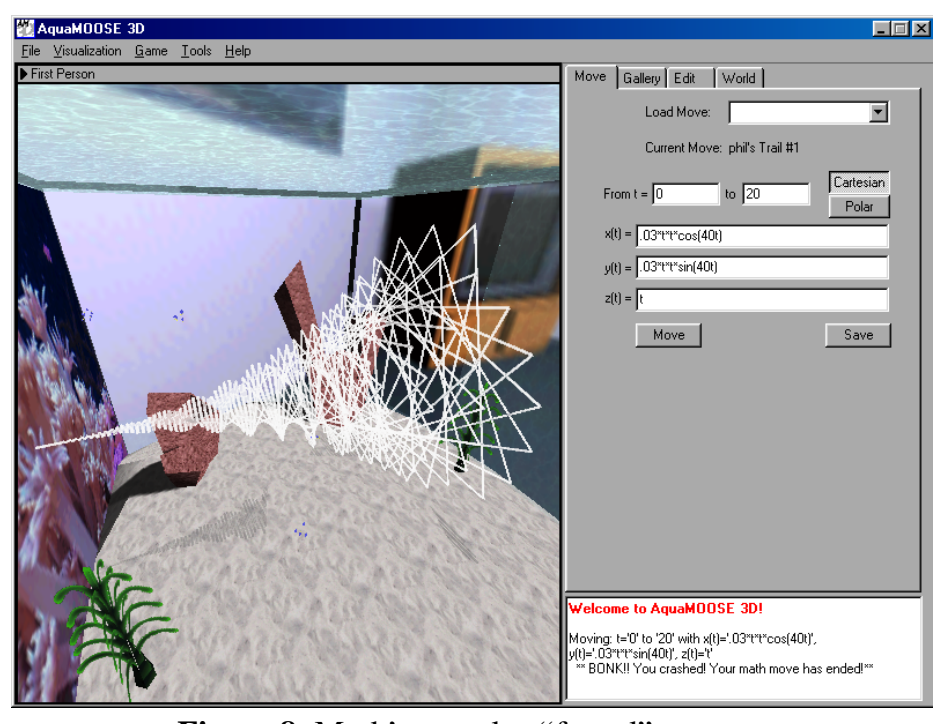

Figure 8: Mark's complex “funnel” move.

$$
\begin{gathered}
x(t)=.03 * t * t * \cos (40 t) \\
y(t)=.03 * t * t * \sin (40 t) \\
z(t)=t
\end{gathered}
$$

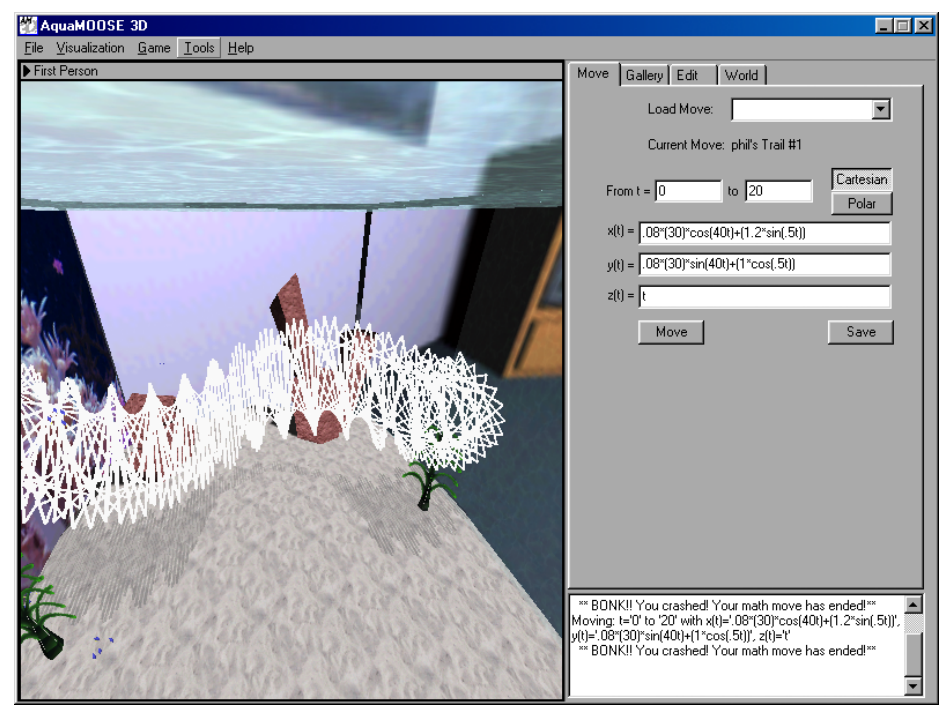

Figure 9: Mark's "spiral spiral” move.

$$
\begin{gathered}
x(t)=.08 *(30) * \cos (40 t)+(1.2 * \sin (.5 t)) \\
y(t)=.08 *(30) * \sin (40 t)+(1 * \cos (.5 t)) \\
z(t)=t
\end{gathered}
$$

\section{FUTURE WORK}

Mark's experiences are a good sign. Mark and many other students particularly found the aesthetics of the environment motivating. If it is possible for one student to become so deeply engaged, it is certainly possible for others like him. As we refine our system design, 
we should be able to broaden its appeal over time. However, our results can also be viewed as quite discouraging. We must also ask, why didn't more of the students become excited about AquaMOOSE? In this study, we created near ideal conditions. Our subjects are a group of students with both unusual ability and unusual interest in the subject matter. They had access to excellent computer hardware (which many do not at either home or school). Furthermore, they had this access in a shared laboratory where they could observe one another's work and exchange ideas. Why didn't they all become as absorbed as Mark? Some of the reasons no doubt concern the early stage of refinement of the software, but others are of broader significance.

Some of the students, like Mark, initially tried to express equations in terms of the wrong variables. Many did not make it past this initial hurdle as Mark did. Several also spent more of their time using the AquaMOOSE avatar construction kit, instead of exploring mathematical ideas. The avatar construction kit allows you to customize your fish by swapping in different parts like fin shapes and changing surface textures. In general, there was a great deal of competition for the students' time. After doing math all day, many did not want to take a "busman's holiday" by doing more math in their precious free time. Providing a viable alternative in the competition for teens' attention is a central goal of the project, and one which we will continue to strive towards.

One usability issue that appears particularly challenging to solve concerns the size of the graphical environment. In most implementations of the Logo programming language, the 2D space available is extremely limited, but wraps. Leave one side of the screen and you reappear exactly opposite. However, the mathematics in Logo is always relative to the position of the user's avatar (the turtle). In AquaMOOSE, we are explicitly trying to help students learn about absolute Cartesian and polar coordinate systems. To leave the space at one coordinate and re-enter at a different one would be confusing. Instead, in our implementation hitting the edge of the space simply generates a collision and the avatar stops with an error message. However, the problem most often mentioned in our student questionnaires was "bonking" into walls. Since the trial at GHP, we have created a number of larger environments to create more space for students to work. However, note that AquaMOOSE supports manual movement of the user's avatar in addition to movement specified by mathematical equations. Currently this movement is at a fixed speed. Moving manually, getting from one side to another of our new larger spaces is quite tedious. We are exploring the possibility of supporting variable speed movement. How to make this new feature intuitive is a challenge, since the movement interface for generating 3D movement from a 2D input device (the mouse) is already complicated. We will continue to explore solutions to this problem.

To return to our earlier analogy, creators of public television face substantial challenges. Funded by government grants and charitable contributions, they typically cannot begin to approach the production values of commercial television. Our undertaking is similar. For example, to create the massively multiplayer online role-playing game Asheron's Call, Turbine Entertainment had a staff of over 30 people working for 4 years [16]. That staff included highly trained professionals with years of specialized experience in networking, sound design, 3D artwork, etc. In developing AquaMOOSE, we have a few computer science graduate students and undergrads, and one faculty member. This limitation is not unique to our situation, but fundamental to the medium. To continue the analogy, many viewers of network television enjoy watching violent shows. Violence is an easy way to capture people's attention. Public television eschews this, needing to find other ways to attract and keep people's attention. This is even truer in our case: violence pervades the majority of computer games, and creating an appealing game with no violent content is challenging. Finally, public television has a harder fundamental task than network TV: it must not only entertain, but also enlighten. In our design of AquaMOOSE, we face this same challenge.

We have made initial inroads into designing an activity that will be both fun and educational, but our model will need to continue to evolve over time. We are encouraged by the enthusiasm of Mark and the handful of other students who became fascinated with our 'public interactive 3D' prototype. Even after packed days of math instruction, they chose to spend substantial amounts of their free time exploring mathematical forms with our software.

Looking forward, our immediate research goal is to revise the software based on feedback from their experiences. Starting in February 2002, we will conduct a set of formal trials of math learning facilitated by AquaMOOSE at Brooks High School and Atwood Private School. These studies will have a comparison class design and use both quantitative and qualitative measures to rigorously assess student learning. At the same time, we are working towards a public release of the software. Mark is looking forward to the ability to use it at home, and we hope he and others like him will form a mutually supportive user community online.

\section{Conclusions}

Our initial four years of work on the AquaMOOSE project first and foremost serve as a proof of concept: 3D graphical environments have significant potential to support new forms of mathematical learning. They can provide the two hallmarks of good constructionist learning environments: personal connections to things that interest students and epistemological connections to new areas of knowledge. While usability challenges of 3D interface design are substantial, these appear to be surmountable with careful design work.

Second, through this work we have gained deeper insight into the costs and benefits of big-picture design thinking. We chose to focus on matching the affordances of the medium to intellectual ideas, and give lower priority to users' immediate needs. While this may at one level seem like bad design process, a step back offers a different perspective. The current curriculum was, after all, designed based on the affordances of old technology, as Papert notes. New technology 
can make different mathematical ideas accessible and salient. However note that neither the curriculum (designed for old technology) nor innovative designs supported by new technology address the more fundamental question of what students really need to know. Why do we want students to learn math anyway? What intellectual and practical imperatives should be at work? Fundamental reform of school curricula is needed. We can take better advantage of learning opportunities provided by new technology and also account more carefully for real learning needs of students.

Finally, in our trials of AquaMOOSE to date we were surprised by the broad variety of visualization ability demonstrated by students. Joel and Mark thrive in this kind of environment, but not all their peers have the same level of understanding. Even within Joel's honors class at a top-ranked high school, a surprising level of variability was observed. In future work, we hope to better understand what cognitive elements lead to this wide variability. A deeper understanding of cognitive phenomena at work has significant implications for the design of 3D interactive systems.

\section{ACKNOWLEDGMENTS}

We would like to thank the teachers and students at GHP for their help, especially Sean Molley and Dennis Stewart. In addition, we would like to thank the teachers and students at Brooks High School and Atwood Private School. Thanks also to Lori Adams, Elizabeth Edwards, Rachel Fithian, Philip Graham, Stuart Jeff, Scott Lewis, and Jonathan Smiley for their contributions. The AquaMOOSE project is supported by an NSF CAREER Grant, Award REC-9876168.

Additional support was provided by Intel.

\section{CONTACT INFORMATION}

Jason Elliott and Amy Bruckman

College of Computing

Georgia Institute of Technology

Atlanta, GA 30332-0280

\{jlelliot, asb\}@cc.gatech.edu

http://www.cc.gatech.edu/elc/

\section{REFERENCES}

1. Brooks, F.P., Grasping Reality Through Illusion -- Interactive Graphics Serving Science, in Proc. of CHI '88. 1988. p. 1-11.

2. Bruckman, A., Community Support for Constructionist Learning. CSCW Journal, 1998. 7: p. 47-86.

3. Bruckman, A. and E. Edwards, Should We Leverage NaturalLanguage Knowledge?, in Proc. of CHI '99. 1999 p. 207-214.
4. Conway, M., et al., Alice: Lessons Learned from Building a 3D System for Novices, in Proc. of CHI '00. 2000 p. 486-493.

5. Cypher, A. and D.C. Smith, KidSim: End User Programming of Simulations, in Proc. of CHI '95. 1995. p. 27-34.

6. Dede, C., et al., Multisensory Immersion as a Modeling Environment for Learning Complex Scientific Concepts, in Modeling and Simulation in Precollege Science and Mathematics, W. Feurzeig and N. Roberts, Editors. 1999, Springer Verlag: USA.

7. Dugdale, S., Green Globs: A Microcomputer Application for Graphing of Equations, in NCTM's Mathematics Teacher. 1982. p. 208-214.

8. Eisenberg, M. and A. Nishioka, Creating Polyhedral Models by Computer. Journal of Computers for Mathematics and Science Teaching, 1997. 16(4): p. 477-512.

9. Entertainment, E., Genesis3D: Open Source Project, 1998 (http://www.genesis3d.com).

10. Guzdial, M. and K. Rose, Squeak: Open Personal Computing and Multimedia. 2001, USA: Prentice Hall. 528.

11. Kafai, Y. and I. Harel, Children Learning Through Consulting, in Constructionism, I. Harel and S. Papert, Editors. 1991, Ablex Publishing: Norwood, NJ. p. 110-140.

12. Nielsen, J., 2D is better than 3D, 1998.

13. Papert, S., Mindstorms: Children, Computers, and Powerful Ideas. 1980, New York: Basic Books.

14. Papert, S., Situating Constructionism, in Constructionism, I. Harel and S. Papert, Editors. 1991, Ablex Publishing: Norwood, NJ. p. 518.

15. Rader, C., C. Brand, and C. Lewis, in Proc. of CHI '97, 1997. p. 351358 .

16. Ragaini, T., Turbine's Asheron's Call, in Game Developer. 2000. p. 54-66.

17. Repenning, A., A. Ioannidou, and J. Phillips, Collaborative Use \& Design of Interactive Simulations, in Proc. of CSCL. 1999: Palo Alto, CA. p. $475-487$.

18. Resnick, M., A. Bruckman, and F. Martin, Pianos Not Stereos: Creating Computational Construction Kits, in Interactions. 1996.

19. Tan, D.S., G.G. Robertson, and M. Czerwinski, Exploring 3D Navigation, in Proc. of CHI '01. 2001. p. 418-425.

20. Verant Interactive, EverQuest, 1999 (http://www.everquest.com).

21. Verant Interactive, Sony Online Entertainment to Introduce New EverQuest Servers in European Markets, 2001 (http://www.verant.com/press_releases.html).

22. Vinson, N.G., Design Guidelines for Landmarks to Support Navigation in Virtual Environments, in Proc of CHI '99. 1999. p. 278-285.

23. Yee, N., The Norrathian Scrolls: A Study of Everquest (v 2.5), 2001 (http://www.nickyee.com/eqt/report.html) 